\title{
Subclinical thyroid dysfunction among pregnant women with bad obstetrical history
}

\begin{abstract}
Background: Subclinical maternal thyroid dysfunction adversely affects the obstetrical outcome. Treatment of subclinical hyper or hypothyroidism clearly improves the pregnancy outcome. Therefore screening of thyroid function in pregnancy is the need of time.
\end{abstract}

Objective: To determine the frequency of subclinical thyroid dysfunction among pregnant women with bad obstetrical history

Design: Cross sectional study

Sampling technique: Non-probability convenient sampling

Materials and methods: This study was done at Chohan Reproduction and Assisted Fertility Treatment Center (CRAFT-IVF) in duration of 2 year. 260 pregnant women of age 18-40years with bad obstetrical history were enrolled. Informed consent was obtained and demographic history like, age, gestational age, obstetrical details were taken. Blood samples were taken for thyroid hormones i.e. fT3, fT4, and TSH levels in first antenatal visit in outpatient department. Interpretation of thyroid dysfunction was done. Data analysis was done on SPSS version 16.0.Mean and standard deviation calculated for fT4, fT3 and TSH. Frequency and percentages were calculated for subclinical thyroid dysfunction.

Results: 260 pregnant females were enrolled in study to evaluate subclinical thyroid dysfunction. Mean age of the patients was $30.31+3.11$. Mean fT4 level was $1.84 \pm 1.12 \mathrm{ng} / \mathrm{dl}$, fT3 $2.62+1.14 \mathrm{ng} / \mathrm{dl}$ and TSH level was $4.32 \pm 0.91 \mathrm{mIU} / 1$. Thyroid dysfunction was observed in $118(45.4 \%)$. Out of which subclinical hypothyroidism was noted in $77(65.2 \%)$ pregnant whereas subclinical hyperthyroidism in $41(34.7 \%)$ of patients with bad obstetrical history.

Conclusion: Frequency of subclinical thyroid dysfunction is high in our population so it should be considered and managed in pregnant women especially with bad obstetrical history.

Keywords: bad obstetric history, thyroid dysfunction, subclinical hypothyroidism
Volume 4 Issue I - 2017

\author{
Fauzia Butt,' Arshad Chohan² \\ 'Department of Gynecology and Obstetrics, Sharif Medical and \\ Dental College, Pakistan \\ ${ }^{2}$ King Edward Medical University, Pakistan \\ Correspondence: Fauzia Butt, Department of Gynecology \\ and Obstetrics, Sharif Medical and Dental College,Visiting \\ Consultant Sharif Medical City Hospital, Raiwind Road, 138 - L \\ Block Valancia, Lahore, Pakistan, Tel 03009427094, \\ Email drfauziabutt@hotmail.com, drfauziabutt@gmail.com
}

Received: October 30, 2016 | Published: January 12, 2017

\section{Introduction}

Thyroid gland undergoes major change in its function during pregnancy. This has been reflected by $50 \%$ increase in production of thyroxin (T4) and tri-iodothyronine (T3) with an increase in iodine requirement. So euthyroid mother in the beginning of pregnancy becamehypothyroid in later part that had iodine deficiency. ${ }^{1}$ Modern studies describe thyroid disease as the second most frequent endocrine disorder that can affect women in their reproductive age. ${ }^{2}$ When thyroid disease remains untreated in a pregnant woman some disorders can appear. This include increased risk of miscarriage, hypertension, growth restriction, and placental abruption, and preterm births. ${ }^{3}$ American Association of Endocrinologist (AAS) recommended that screening should be done in all pregnant women during first trimester. However expert panel of AAS and European and American thyroid Association does not recommend universal screening however testing in high risk group is recommended. ${ }^{4}$ If every pregnant was screened in antenatal period for TSH levels and thyroid autoantibodies high percentage of women with subclinical hypothyroidism will be detected. For this reason Gafoor et al. ${ }^{5}$ in Pakistan determine the prevalence of thyroid peroxidase antibodies among euthyroid pregnant women and its relation to pregnancy outcome. His results showed $11 \%$ prevalence of thyroid peroxidase antibodies and high abortion, preterm births among these pregnant woman. ${ }^{5}$ Pakistan is iodine deficient country plus an iodine deficient diet place Pakistani pregnant woman at risk of developing adverse pregnancy outcome and maternal hypothyroidism. ${ }^{6}$ Women with history of unexplained stillbirth/neonatal death, three or more consecutive abortions are labeled as to have bad obstetrical history (BOH). ${ }^{7}$ In approximately $40.51 \%$ women, no probable cause of $\mathrm{BOH}$ could be identified. A higher incidence of malpresentation, hypertension, antiphospholipid antibody syndrome, cervical incompetence, preterm deliveries and caesarean section has been documented in these patient. ${ }^{8}$ The aim of this study was to determine the frequency of subclinical thyroid dysfunction among pregnant women with bad obstetric history. Women with bad obstetric history may have maternal and neonatal problems in next pregnancy. In majority of cases, cause of bad obstetrical history is not known so improvement in prognosis not possible. Since, thyroid dysfunctions are also associated with worse maternal and fetal outcome; this may also be present in women with bad obstetric history. Moreover controversial results are present in literature some reporting it as significant while other reported as 
negligible. So, this study is conducted in order to confirm the rate of subclinical thyroid dysfunction among pregnant women in order to determine whether this may be of cause of $\mathrm{BOH}$ or not. By knowing the frequency of thyroid dysfunction guide us in developing the screening and management strategies and iodine supplementation among pregnant with bad obstetric history.

\section{Material and methods}

This cross sectional study was conducted in Chohan Reproduction and Assisted Fertility Treatment Center (CRAFT-IVF) in 2year duration from October 2013 to October 2015. Using non-probability; convenient sampling technique 260 pregnant women were recruited. Sample size of 260 cases was calculated with $95 \%$ confidence level, $3 \%$ margin of error and expected percentage of subclinical hypothyroidism $6.47 \%$ in pregnant women with bad obstetrical history. ${ }^{9}$ Patients included in study were all pregnant women of age 18-40years with bad obstetrical history BOH (unexplained stillbirth/neonatal death, three or more consecutive miscarriages, congenital anomalies, and intrauterine growth restriction). Patients excluded from study were those with previous history of thyroid surgery, on antipsychotic drugs, beta blockers, thyroxin, neomercazol, and patients with twin pregnancy. After informed consent detailed history was taken including gage, duration of pregnancy, parity, and obstetrical history including recurrent miscarriages, stillbirths, and neonatal deaths. Booking status was noted. Women were inquired about personal and family history of thyroid disease. Frequency of antenatal care in previous pregnancies was also inquired. Patients were inquired about intake of meat, iron supplementation, and iodized salt in diet. Nutritional status was assessed by body mass index, pallor, and by thyroid enlargement (goiter). All patients were assessed with the thyroid hormone levels by drawing blood in $5 \mathrm{cc}$ syringe. Samples were sent to laboratory of the hospital for assessment of free T3, free T4 and TSH level on commercially available radioimmunoassay kit (Beckman Caulter). Reports were interpreted by Pathologist to evaluate for presence of thyroid dysfunctions. Thyroid dysfunction classified on the basis of TSH, fT3 and fT4 level according to American Thyroid Associations Guidelines during pregnancy as subclinical hypothyroidism if high TSH $(2.5-10.0 \mathrm{mIU} / \mathrm{L})$ with normal fT4 value $(0.7-1.8 \mathrm{ng} / \mathrm{dL})$ and subclinical hyperthyroidism as low TSH $(<0.1 \mathrm{mIU} / \mathrm{L})$ with normal fT4 $(0.7-1.8 \mathrm{ng} / \mathrm{dL})$. All women were followed until delivery. Women suffering from subclinical hypothyroidism were treated with levothyroxin. Maternal outcome studied were threatened abortion, preterm delivery, and gestational hypertension. Data was collected in a specially designed proforma and entered into SPSS version 16. Quantitative data like age, fT3, fT4 and TSH level were presented as means and standard deviation and qualitative data like presence of thyroid dysfunction (yes or no) was presented as frequency and percentages. Categories of thyroid dysfunction i.e. subclinical hyper or hypothyroidism was also presented as frequency and percentages.

\section{Results}

260 females, who were enrolled in this study to evaluate the thyroid dysfunction, mean age of pregnant women was noted to be $30.31+3.11$ years. Out of 260 females $182(70 \%)$ were un-booked and never receive an tenatal care in previous pregnancies. $72 \%$ of pregnant women were uneducated. Among these women 30\% were receiving iodized salt and thyroid enlargement was observed in $45 \%$. $58 \%$ women were anemic and belong to poor socioeconomic class (65\%).Mean fT3 level was $2.62+1.14 \mathrm{ng} / \mathrm{dl}$, fT4 level $1.84 \pm 1.12 \mathrm{ng} /$ $\mathrm{dl}$ and TSH level was $4.32 \pm 0.91 \mathrm{mIU} / 1$ (Table 1). There were total $118(45.4 \%)$ pregnant women who were diagnosed with thyroid dysfunction and 142(54.6\%) were euthyroid (Table 2). Out of 118 pregnant women with thyroid dysfunction subclinical hypothyroidism was noted in $77(65.3 \%)$ of women, and subclinical hyperthyroidism among 41(34.7\%) women with bad obstetrical history (Table 3).

Table I TSH, fT4, fT3 concentrations in women with bad obstetrical history

\begin{tabular}{llll}
\hline & $\begin{array}{l}\text { fT3 }(\mathbf{n g} / \\
\text { dL) }\end{array}$ & $\begin{array}{l}\text { fT4 }(\mathbf{n g} / \\
\text { dL) }\end{array}$ & $\begin{array}{l}\text { TSH } \\
(\mathbf{m I U} / \mathbf{L})\end{array}$ \\
\hline Mean & 2.62 & 1.84 & 4.32 \\
Standard deviation & 1.34 & 1.12 & 0.91 \\
\hline
\end{tabular}

Table 2 Frequency of thyroid dysfunction among women with bad obstetrical history

\begin{tabular}{lll}
\hline Thyroid dysfunction & No of patients & Percent \\
\hline Yes & 118 & 45.4 \\
No & 142 & 54.6 \\
Total & 260 & 100.0
\end{tabular}

Table 3 Frequency of subclinical thyroid dysfunction among pregnant women

\begin{tabular}{lll}
\hline Thyroid dysfunction & No of Patients & Percent \\
\hline Subclinical Hypothyroidism & 77 & 65.3 \\
Subclinical Hyperthyroidism & 41 & 34.7 \\
Total & 118 & 100.0 \\
\hline
\end{tabular}

\section{Discussion}

Thyroid dysfunction is the second most common endocrine problem encountered in 2-3\% of woman in pregnancy. ${ }^{10}$ Adverse fetomaternal outcome has not only observed in overt but in subclinical hypothyroidism as well. ${ }^{11}$ In study conducted by Ohashi $\mathrm{M}$ et al. ${ }^{12}$ prevalence of thyroid dysfunction during pregnancy was $24.7 \%$. Hypothyroidism in $16.8 \%$ (overt $=4.5 \%$, subclinical $=83.3 \%$ ) while hyperthyroidism in $7.9 \%$ (overt $=0 \%$, subclinical $=83.9 \%$ ). ${ }^{12}$ In few other studies incidence of sub clinical hypothyroidism was 2 to $3 \%$, of which overt hypothyroidism 0.3 to $0.5 \%$ and of hyperthyroidism 0.1 to $0.4 \%$ during pregnancy. ${ }^{13,14}$ In Pakistan a study conducted by Elahi et al., ${ }^{6}$ about $79.8 \%$ of pregnant woman were iodine deficient out of $28.7 \%$ were moderately deficient in iodine. ${ }^{6}$ Local data regarding true prevalence of subclinical hyo or hyperthyroidism is missing in pregnant women. Prevalence of thyroid dysfunction varies in different population. In one study conducted in Iran $9.8 \%$ had subclinical and overt hypothyroidism while $4.8 \%$ had overt and subclinical hyperthyroidism. In china reported prevalence was $10 \%$, hypothyroidism in $9.8 \%$ (subclinical $7.4 \%$, and overt $2.4 \%$ ) while in European and American pregnant women reported prevalence is $2.2 \%$ to $2.5 \%$, Considering high prevalence of thyroid dysfunction in developing countries priority to thyroid dysfunction must be given despite the cost of test involved. ${ }^{15}$ In our study prevalence of thyroid dysfunction was observed in $118(45.4 \%)$ pregnant women with $\mathrm{BOH}$. In this study the frequency of thyroid dysfunction was high due to uneducational status, poor socioeconomic status, micronutrient deficiency i.e. iron supplementation and iodized salt, and lack of health care facilities during pregnancy. There is slight but significant 
difference in serum TSH concentrations in pregnant women. Black and Asian women have TSH values that are on average $0.4 \mathrm{mIU} / \mathrm{L}$ lower than in white women; these differences persist during pregnancy. ${ }^{16,17}$ This study was carried out according to this new criterion of thyroid function during pregnancy. The mean TSH concentration in our pregnant women was $4.2 \pm 0.91 \mathrm{mU} / \mathrm{L}$. The American Thyroid Associations (ATA) recommendations guide us not only in determination of exact prevalence but in correct interpretation of data to avoid adverse feto-maternal outcome of thyroid dysfunction. ${ }^{18}$

In our study $118(65.3 \%)$ pregnant woman with bad obstetrical history thyroid dysfunction was diagnosed. Prevalence of subclinical hypothyroidism was found in 77 (65.3\%) and subclinical hyperthyroidism in $37.4 \%$. In our study high percentage of women suffers from thyroid dysfunction as we only study high risk group of bad obstetrical history which were undiagnosed before. Screening all pregnant women might give different picture. Studies conducted in Pakistan by Elahi et al., ${ }^{6}$ over pregnant women reveal that $79.8 \%$ of pregnant women were iodine deficient out of which $24.7 \%$ were moderately deficient which predisposes these women and their neonates to iodine deficiency disorders. ${ }^{6}$ India and Pakistan are the countries where the spectrum of prevalent disease share common factors in their cure and prevention. So Rafia Afzal in article review over thyroid disorders in Pakistan revealed the fact that in Pakistan we lack data regarding true prevalence of thyroid dysfunction in pregnancy and their fetal outcome. ${ }^{19}$ So iodine supplementation should be part of prevention strategies in Pakistani pregnant women. The occurrence of subclinical hyperthyroidism in our study was $34.7 \%$. In a study done by Sahu MT et al., ${ }^{19}$ the prevalence was $0.9 \%$ for subclinical hyperthyroidism. ${ }^{18}$ The occurrence of subclinical hyporthyroidism in our study was $65.3 \%$ thus it is more prevalent in our population which place all these women at greater risk of complications. Study by Karakosta P. Alegak is reveal that hypothyroidism is associated with 3.8 times higher risk of developing gestational hypertension (p.0001), rate of cesarean section (51.3\%) and PPH (12.8\%) despite replacement therapy in hypothyroid mothers. So good multidisciplinary team approach in tertiary care hospitals is the need of time where the services of endocrinologist and experienced obstetrician in high risk cases will improve obstetrical outcome..$^{20}$ Preeclampsia is a frequent problem in both overt hypothyroidism and hyperthyroidism and less likely in women with subclinical thyroid dysfunction..$^{21,22}$ In this study threatened abortion was observed in $0.5 \%$. pre-eclampsia in $6.3 \%$ and preterm delivery in $13 \% .{ }^{23}$ Hypothyroidism adversely affects the fetal brain development as it is vital for maturation and functioning of neurons. Studies have confirmed that low thyroid hormone with thyroid peroxidase antibodies associated with significant decrements of IQ of children when tested at 7year and 10months.In this study we did not do long term follow ups of children however in future studies must be done in Pakistan to see our results on cognitive development of children. ${ }^{24-26}$ Limitation of this study was that we did not perform thyroid peroxidase antibodies testing a major cause for thyroid dysfunction and urinary iodine status to assess the deficiency of iodine intake among these pregnant women because of cost involved in testing.

\section{Conclusion}

Frequency of subclinical thyroid dysfunction is high in our population. Effective prevention and treatment strategies must be implemented to reduce the prevalence of subclinical thyroid dysfunction during pregnancy in our population. For effective prevention, screening of all high risk patients should be encouraged including thyroid function testing, thyroid peroxidase auto antibodies testing and urinary iodide concentration. Government should identify obstacles in iodine supplementation program. All booked patients should be encouraged to take $250 \mathrm{~m} \mu \mathrm{g}$ iodine/day in their diet either from food (sea food) or iodized salt or prenatal vitamin supplementation containing $150 \mathrm{~m} \mu \mathrm{g}$ iodine. Administration of levothyrothyroxin to reduce the risk of complications in women with subclinical hypothyroidism. As it is safe, cheap, easily available, well tolerated and has prove its worth in prevention of complication of high risk group.

\section{Acknowledgements}

None.

\section{Conflict of interest}

The author declares no conflict of interest.

\section{References}

1. Burrow GN, Fisher DA, Larsen PR. Maternal and Fetal thyroid function. N Engl J Med. 1994;331(16):1072-10728.

2. Haddow JE, McClain MR, Lambert-Messerlian G, et al. Variability in thyroid - stimulating hormone suppression by human chorionic gonadotrophin during early pregnancy. $J$ Clin Endocrinol Metab. 2008;93(9):3341-3347.

3. Gluud C, Gluud LL. Evidence based diagnostics. BMJ. 2005;330(7493):724-726.

4. Stagnaro-Green A, Abalovich M, Alexander E, et al. Guidelines of the American Thyroid Association for the diagnosis and management of thyroid disease during pregnancy and postpartum. Thyroid. 2011;21(10):1081-1125.

5. Ghafoor F, Mansoor M, Malik T, et al. Role of thyroid peroxidase antibodiesin the outcome of pregnancy. $J$ Coll Physicians Surg Pak. 2006;16(7):468-471.

6. Elahi S, Rizvi NB, Nagra SA. Iodine deficiency in pregnant women of Lahore. J Pak Med Assoc. 2009;59(11):741-743.

7. Ranganath P, Lucas M, Rajangam S. Bad obstetric history (BOH) seminal causes. Anatomica Kamataka. 2004;1:18-21.

8. Singh G, Sindhu M. Bad obstetric history; a prospective study. Med $J$ armed Forces India. 2010;66(2):117-120.

9. van den Boogaard E, Vissenberg R, Land JA, et al. Pregnancy thyroid screening: Significance of subclinical thyroid dysfunction and thyroid autoimmunity before conception and in an early pregnancy: A systemic review. Human Reprod Update. 2011;17(5):605-619.

10. Shah JM, Mehta MN, Viradia HB. Screening for thyroid dysfunction during pregnancy. Thyroid Res Pract. 2013;10(2):65-67.

11. Saharabuddhe A, Pitale S. Screening for thyroid dysfunction during pregnancy. Thyroid Res Pract. 2012;9(1):15-17.

12. Ohashi M, Furukawa S, Michikata K, et al. Risk-Based Screening for Thyroid Dysfunction during pregnancy. J Preg. 2013;2013:619-718. 
13. Joshi S, Raut V. Thyroid womb to tomb. Fogsi Focus. 2006. p. 1-7.

14. Kyariazoopoulou V, Michalaki M, Georgopoulos N, et al. Recommendations for thyroxin therapy during pregnancy. Expert OpinPharmacother. 2008;9(3):421-427.

15. Karger S, Führer Sakel D. Thyroid disease and pregnancy. Med Klin (Munich). 2009;104(6):450-460.

16. Yassaee F, Farahani M1, Abadi AR. Prevalance of subclinical hypothyroidism in Pregnant Women in Tehran-Iran. Int $J$ FertiSteril. 2014;8(2):163-166

17. Cotzias C, Wong SJ, Taylor E, et al. A study to establish gestation specific reference intervals for thyroid function tests in normal singeeton pregnancy. Eur J Obstet Gynecol Reprod Biol. 2008;137(1):61-66.

18. Carney LA, Quinlan JD, West JM. Thyroid disease in pregnancy. Am Fam Physcian. 2004;89(4):273-278.

19. Sahu MT, V Das, S Mittal, et al. Overt and subclinical thyroid dysfunction among Indian pregnant women and its effect on maternal and fetal outcome. Arch Gynecol Obstet. 2010;281(2):215-220.

20. Afzal R. Thyroid disorders in pregnancy: An overview of literature from Pakistan. Indian J Endocrinol Metabol. 2013;17(5):943-945.
21. Karakosta P, Alegakis D, Georgiou V, et al. Thyroid dysfunction and autoantibodies in early pregnancy are associated with increased risk of gestational diabetes and adverse birth outcome. J Clin Endocrinol Metab. 2012;97(12):4464-4472.

22. Wartofsky L, Burman K. Alterations in thyroid function in patients with systemic illness: the "euthyroid sick syndrome". Endocr Rev. 1982;3(2):164-217.

23. Nirmala C, Jayakumari C, Rajaesekharan C, et al. Maternal outcome of hypothyroidism in pregnancy-a south Indian perspect. American $J$ Clinical Medical Research. 2014;2(2):47-50.

24. Williams GR. Neurodevelopmental and neurophysiological actions of thyroid hormones. J Neuroendocrinol. 2008;20(6):784-794.

25. Man EB, Brown JF, Serunian SA. Maternal Hypothyroixenimia:psychoneurologicaldeficit of progeny. Ann Clin Lab Sci. 1991;21(4):227-239.

26. Pop VJ, Kuijpens JL, van Baar AL, et al. Low maternal free thyroxin concentrations during early pregnancy are associated with impaired pshycomotor development in infancy. Clin Endocrinol (Oxf). 1999;50(2):147-155. 